Jurnal Kesehatan Terpadu (Integrated Health Journal)

Vol. 12 No. 2, November 2021 (55-61)

ISSN 1978-7766 (Print) and ISSN 2597-9566 (Online)

Journal homepage: https://www.jurnalpoltekkesmaluku.com/index.php/JKT

\author{
Hubungan Sanitasi Lingkungan dengan Stunting pada Anak Balita \\ di Daerah Pesisir Pantai Puskesmas Tumalehu Tahun 2020 \\ Relationship between Environmental Sanitation and Stunting of Children \\ in the Coastal Area of Tumalehu Health Center in 2020
}

\title{
Inamah $^{1}$, Rahwan Ahmad ${ }^{2}$, Wahyuni Sammeng' ${ }^{1}$, Hairudin Rasako
}

\author{
${ }^{1}$ Jurusan Gizi Poltekkes Kemenkes Maluku, Jalan Laksdya Leo Wattimena, Negeri Lama, Ambon \\ ${ }^{2}$ Jurusan Sanitasi Poltekkes Kemenkes Maluku, Jalan Laksdya Leo Wattimena, Negeri Lama, Ambon \\ E-mail Korespondensi: inamah76@gmail.com
}

\begin{abstract}
Poor environmental sanitation will result in diarrheal disease which will later lead to infection and thus lead to malnutrition. In Indonesia, it is recorded that 7.8 million out of 23 million children under five are stunted or around 35.6\%. Based on the Tumalehu Health Center report (November 2019), it shows that in 2019 the number of children under five was 1467 and those with poor nutritional status were 89 children $(6.07 \%)$. The research objective was to analyze the relationship between environmental sanitation and stunting in children under five in the coastal area of Tumalehu Health Center. This research method is analytic observational with a cross-sectional approach, the number of samples is 313 toddlers. Data were analyzed using Chi Square Test. The results of the study using a bivariate test showed that there was a relationship between environmental sanitation, consisting of clean water facilities $(\mathrm{p}=0.014)$, SPAL $(\mathrm{p}=0.05)$ and waste disposal facilities $(\mathrm{p}=0.00)$ with the incidence of stunting (HAZ) in toddler. The conclusion from the research is that poor sanitation can contribute to nutritional problems, in this case a picture of past nutrition problems for children under five, which is indicated by stunting.
\end{abstract}

Keywords: Environmental sanitation, stunting

\section{ABSTRAK}

Salah satu prioritas pembangunan kesehatan dalam Rencana Pembangunan Jangka Menengah Nasional (RPJMN) tahun 2015-2019 adalah perbaikan gizi dan sanitasi lingkungan. Sanitasi lingkungan yang tidak baik dapat mengakibatkan penyakit diare yang akan menyebabkan infeksi sehingga terjadi kekurangan gizi. Di Indonesia tercatat 7,8 juta dari 23 juta balita adalah penderita stunting atau sekitar 35,6\%. Berdasarkan laporan Puskesmas Tumalehu (November 2019), menunjukkan bahwa jumlah balita yang ada pada wilayah kerjanya di tahun 2018 berjumlah 1421 anak, dengan status gizi kurang 93 anak $(6,25 \%)$ dan di tahun 2019 balita berjumlah 1467 anak dengan status gizi kurang 89 anak (6,07\%). Tujuan penelitian adalah menganalisis hubungan sanitasi lingkungan dengan stunting pada anak balita di daerah pesisir pantai Puskesmas Tumalehu. Metode penelitian ini analitik observasional dengan pendekatan cross-sectional, jumlah sampel sebanyak 313 balita. Data dianalisis dengan menggunakan Uji Chi Square. Hasil penelitian dengan uji bivariat menunjukkan bahwa terdapat hubungan sanitasi lingkungan yaitu sarana air bersih $(p=0.014)$, SPAL $(p=0,05)$ dan sarana tempat pembuangan sampah $(p=0,00)$ dengan kejadian stunting (TB/U) pada balita. Kesimpulan pada penelitian bahwa sanitasi yang buruk dapat memberi kontribusi masalah gizi dalam hal ini gambaran masalah gizi masa lampau balita yang ditunjukkan adanya stunting.

\section{Kata kunci: Sanitasi lingkungan, stunting}


Jurnal Kesehatan Terpadu (Integrated Health Journal)

Vol. 12 No. 2, November 2021 (55-61)

ISSN 1978-7766 (Print) and ISSN 2597-9566 (Online)

Journal homepage: https://www.jurnalpoltekkesmaluku.com/index.php/JKT

\section{PENDAHULUAN}

Stunting merupakan prediktor rendahnya kualitas sumber daya manusia yang berdampak menimbulkan risiko penurunan kemampuan produktivitas suatu bangsa. Hal ini membuat pencegahan dan penanggulangan stunting menjadi sangat penting. Secara global, sanitasi masih menjadi masalah di berbagai belahan dunia ${ }^{1}$. Laporan WHO (2015) menyebutkan bahwa dari sekian miliar penduduk dunia yang telah memperoleh akses sanitasi yang memadai hanya sekitar $68 \%$. Meski demikian hasil tersebut telah terjadi peningkatan dari 25 tahun lalu akses sanitasi hanya dapat diperoleh 54\% dari penduduk dunia ${ }^{2}$.

Kementerian PPN/Bappenas mencatat, Indonesia termasuk ke dalam 17 negara yang mengalami beban ganda permasalahan gizi. Berdasarkan Global Nutrition Report pada tahun 2014, di Indonesia tercatat 7,8 juta dari 23 juta balita adalah penderita stunting atau sekitar $35,6 \%$ dengan sebanyak $18,5 \%$ kategori sangat pendek dan $17,1 \%$ kategori pendek. WHO menetapkan batas toleransi stunting maksimal $20 \%$ atau seperlima dari jumlah keseluruhan balita. Hal ini juga yang mengakibatkan WHO menetapkan Indonesia sebagai negara dengan status gizi buruk. Di Indonesia kondisi stunting tertinggi terdapat di Sulawesi Tengah dengan jumlah 16,9\% dan terendah di Sumatera Utara dengan 7,2\%. Dalam RPJMN, pemerintah menargetkan penurun angka prevalensi stunting dari $32,9 \%$ menjadi $28 \%$ pada tahun $2019^{3}$.

Hasil penelitian lain menyebutkan faktor lingkungan berhubungan bermakna $(p<0,05)$ dengan kejadian stunting batita. Pendidikan ayah, pendidikan ibu, pendapatan keluarga, ketersediaan pangan keluarga, dan sanitasi lingkungan keluarga yang rendah mampu meningkatkan 8,5 kali lebih besar risiko anak mengalami stunting 4 .

Data yang dihimpun berita beta.com dari Dinas Kesehatan Provinsi Maluku Juli 2019 menyebutkan bahwa 11 kabupaten/kota yang ada di Maluku, terdapat sebanyak tiga kabupaten yang menjadi lokasi fokus penanganan stunting tahun 2018 dan 2019, yaitu Kabupaten Maluku Tengah, Seram Bagian Barat (SBB), dan Kepulauan Aru. Salah satu faktor yang memicu masalah ini karena penyebab gizi tidak langsung berupa penyakit infeksi yang akan menurunkan kemampuan balita untuk mempertahankan status gizinya. Penyakit infeksi dapat diakibatkan oleh faktor lingkungan (sanitasi buruk). Pemantauan Status Gizi (PSG) tentang prevalensi (jumlah penderita dalam populasi) balita stunting di Maluku dari tahun ke tahun cukup tinggi. Berdasarkan data Riskesdas 2018, angka stunting di Maluku sebesar 31,4\%. Tiga kabupaten yang menjadi fokus perhatian pemerintah untuk menekankan angka stuting kerena lokus (tempat) kasus stunting tertinggi yakni SBB, Maluku Tengah, dan Kepulauan Aru ${ }^{5}$.

Data yang dimiliki pemerintah Kabupaten SBB tahun 2018 menunjukkan bahwa terdapat 1.600 kasus stunting di SBB dan pada tahun 2019 angka tersebut menurun sebesar 18,7\% menjadi 1.300 sehingga masih membutuhkan suatu intervensi. Intervensi yang lakukan melalui Posyandu, Puskesmas, Pustu yang dikawal langsung oleh Kepala Dinas Kesehatan. Selain itu, ada pula langkah-langkah strategis yang dikoordinasi langsung oleh Bappeda. Berdasarkan laporan Puskesmas Tumalehu (November 2019), menunjukkan bahwa jumlah balita yang ada pada wilayah kerjanya tahun 2018 berjumlah 1421 anak, dengan status gizi kurang 93 anak (6,25\%) dan tahun 2019 balita berjumlah 1467 anak dengan status gizi kurang 89 anak $(6,07 \%)^{6}$.

Notoadmojo menyebutkan bahwa sanitasi lingkungan merupakan status kesehatan suatu lingkungan yang mencakup perumahan, pembuangan kotoran, dan penyediaan air bersih. Sanitasi lingkungan dapat pula diartikan sebagai kegiatan untuk meningkatkan dan mempertahankan standar kondisi lingkungan yang mendasar dan mempengaruhi kesejahteraan manusia. Kondisi tersebut mencakup air bersih, Mandi Cuci Kakus (MCK) sampah rumah tangga (limbah padat dan limbah cair), dan drainase ${ }^{7}$.

Lingkungan yang memiliki sanitasi buruk akan berdampak buruk bagi kesehatan. Berbagai jenis penyakit dapat muncul, karena lingkungan yang bersanitasi buruk menjadi sumber berbagai jenis penyakit. Agar terhindar dari berbagai penyakit tersebut, sanitasi 
Jurnal Kesehatan Terpadu (Integrated Health Journal)

Vol. 12 No. 2, November 2021 (55-61)

ISSN 1978-7766 (Print) and ISSN 2597-9566 (Online)

Journal homepage: https://www.jurnalpoltekkesmaluku.com/index.php/JKT

lingkungan harus selalu terjaga, khususnya di pemukiman dan lingkungan sekitarnya. Upaya sanitasi dasar meliputi penyediaan air bersih, pembuangan kotoran manusia (jamban), pengelolaan sampah dan saluran pembuangan air limbah. ${ }^{7}$

\section{METODE PENELITIAN}

Penelitian ini merupakan jenis penelitian analitik observasional dengan desain cross-sectional yaitu jenis penelitian yang menekankan pada waktu pengukuran atau observasi data. Lokasi penelitian dilakukan di daerah pesisir pantai Pulau Seram, provinsi Maluku yang terdiri dari 7 desa dan 1 dusun. Populasi dalam penelitian sebanyak 1470 anak balita. Jumlah sampel sebanyak 313 orang dihitung dengan menggunakan rumus Slovin ${ }^{13}$. Teknik pengambilan sampel dilakukan dengan simple random sampling, yaitu cara pengambilan sampel dengan setiap unsur dari keseluruhan populasi mempunyai kesempatan yang sama untuk dipilih. Pengumpulan data dilakukan dengan pengisian kuesioner melalui teknik wawancara, sedangakan status gizi dilakukan dengan pengukuran antropometri. Sanitasi lingkungan yang diteliti meliputi sarana air bersih, sarana pembuangan limbah, dan tempat pembuangan sampah sedangkan data antropometri meliputi berat badan dan tinggi badan yang diukur menggunakan timbangan digital dan microtoise.

Data dianalisis secara statistik dengan analisis univariat dan bivariat. Analisis univariat yang dilakukan dalam penelitian ini bertujuan untuk mengetahui gambaran karakteristik responden dan analisis bivariat dilakukan untuk mengetahui hubungan sanitasi lingkungan dengan status gizi balita menggunakan uji chi square. Data sanitasi lingkungan dan status gizi balita diolah menggunakan software SPSS versi 20. Sebelum pengambilan data dilakukan, peneliti terlebih dahulu menjelaskan kepada subjek bahwa penelitian bertujuan untuk memenuhi kebutuhan ilmiah dan meminta persetujuan subjek menggunakan informed consent.

\section{HASIL}

Penelitian dilakukan di Puskesmas Tumalehu yang merupakan tempat pelayanan kesehatan di wilayah Kabupaten SBB. Kabupaten ini memiliki penduduk berjumlah 210.607 jiwa pada tahun 2019 dan latar belakang masyarakat sangat beragam, baik suku maupun agama. Sementara itu, pusat pemerintahan berada di Piru, bagian dari Kecamatan SBB, yang berpenduduk 16.628 jiwa. Puskesmas Tumalehu berada di kecamatan Amalatu dengan gambaran wilayah kerja berjumlah 8 desa dan jarak tempuh dari kota Ambon membutuhkan waktu 6 jam.

Tabel 1. Distribusi Responden berdasarkan Pekerjaan dan Pendidikan Terakhir Ibu Balita di Daerah Pesisir Pantai Puskesmas Tumalehu Tahun 2020

\begin{tabular}{cccc}
\hline Variabel & Kategori & Jumlah $\mathbf{( N = 3 1 3 )}$ & Persentase (\%) \\
\hline Pekerjaan & Ibu Rumah Tangga & 123 & 39 \\
& Petani & 130 & 42 \\
& Wiraswasta & 60 & 19 \\
\hline Pendidikan & DIII/S1 & 7 & 2 \\
Terakhir & SMA & 173 & 55 \\
& SMP & 109 & 35 \\
& SD & 24 & 8 \\
\hline
\end{tabular}

Distribusi karakteristik responden dapat dilihat pada Tabel 1 yaitu sebagian besar pekerjaan ibu balita yaitu sebagai petani sebanyak 130 orang (42\%) dan pendidikan terakhir 
Jurnal Kesehatan Terpadu (Integrated Health Journal)

Vol. 12 No. 2, November 2021 (55-61)

ISSN 1978-7766 (Print) and ISSN 2597-9566 (Online)

Journal homepage: https://www.jurnalpoltekkesmaluku.com/index.php/JKT

ibu sebagian besar yaitu SMA sebanyak 173 orang (55\%). Dari jenis pekerjaan ibu balita adalah seorang petani dan pendidikan terakhir adalah SMA, hal ini bisa menunjang kemampuan rumah tangga dalam penyediaan makanan dalam keluarganya.

Tabel 2. Distribusi Status Gizi Balita berdasarkan Indeks TB/U di Daerah Pesisir Pantai Puskesmas Tumalehu Tahun 2020

\begin{tabular}{lcc}
\hline \multicolumn{1}{c}{ Kategori } & Jumlah $(\mathbf{N}=\mathbf{3 1 3})$ & Persentase (\%) \\
\hline Stunting/Pendek (Z-score <-3 SD s.d <-2 SD) & 13 & 4,2 \\
Normal (Z-score -2 SD s.d >+3 SD) & 300 & 95,8 \\
\hline
\end{tabular}

Dari Tabel 2. dapat diketahui bahwa sebagian besar balita yaitu 300 balita $(95,8 \%)$ memiliki indeks status gizi TB/U berada pada kategori normal, dan stunting sejumlah 13 balita $(4,2 \%)$. Hal ini menunjukkan bahwa pada wilayah penelitian masih terdapat masalah kesehatan yaitu ditemukan balita stunting yang perlu mendapatkan perhatian bersama baik pihak orang tua maupun pemerintah dan tenaga kesehatan pada wilayah penelitian.

Tabel 3. Hasil Analisis Sanitasi Lingkungan (Sarana Air Bersih, SPAL, dan Tempat Sampah) dengan Status Gizi (Indeks TB/U) di Daerah Pesisir Pantai Puskesmas Tumalehu Tahun 2020

\begin{tabular}{|c|c|c|c|c|c|c|c|c|}
\hline \multirow{3}{*}{ No } & \multirow{3}{*}{ Sanitasi Lingkungan } & \multicolumn{4}{|c|}{ Status Gizi TB/U } & \multirow{2}{*}{\multicolumn{2}{|c|}{ Total }} & \multirow{3}{*}{$p$-value } \\
\hline & & \multicolumn{2}{|c|}{ Stunting } & \multicolumn{2}{|c|}{ Normal } & & & \\
\hline & & $\mathbf{n}$ & $\%$ & $\mathbf{n}$ & $\%$ & $\mathbf{n}$ & $\%$ & \\
\hline $\mathrm{a}$ & Sarana Air Bersih & & & & & & & \multirow{3}{*}{0.014} \\
\hline 1 & Tidak Memenuhi Syarat & 7 & 9.7 & 65 & 90.3 & 72 & 100 & \\
\hline 2 & Memenuhi Syarat & 6 & 2.5 & 235 & 97.5 & 241 & 100 & \\
\hline $\mathrm{b}$ & Sarana Pembuangan Air Limbah & & & & & & & \multirow{3}{*}{0.05} \\
\hline 1 & Tidak Memenuhi Syarat & 5 & 9.4 & 48 & 90.6 & 53 & 100 & \\
\hline 2 & Memenuhi Syarat & 8 & 3.1 & 252 & 96.9 & 260 & 100 & \\
\hline $\mathrm{c}$ & Tempat Pembuangan Sampah & & & & & & & \\
\hline 1 & Tidak Memenuhi Syarat & 10 & 12.2 & 72 & 87.8 & 82 & 100 & \\
\hline 2 & Memenuhi Syarat & 3 & 0.4 & 228 & 98.7 & 231 & 100 & 0.00 \\
\hline
\end{tabular}

Berdasarkan Tabel 3. dapat diketahui bahwa hasil analisis sanitasi lingkungan dengan status gizi memiliki $p$-value $<0.05$. Analisis sarana air bersih dengan status gizi memiliki $p$ value $=0.014$. Sarana pembuangan air limbah memiliki $p$-value $=0.05$ dan tempat pembuangan sampah memiliki $p$-value $=0.00$. Dengan demikian ada hubungan yang bermakna antara sanitasi lingkungan (sarana air bersih, SPAL dan tempat sampah) dengan status gizi (indeks TB/U).

\section{BAHASAN}

Sanitasi adalah segala upaya untuk menjamin terwujudnya kondisi yang memenuhi persyaratan kesehatan. Sanitasi adalah pengelolaan air bersih, pengelolaan MCK, pengelolaan sampah keluarga, dan drainase untuk menjamin terwujudnya kondisi yang memenuhi persyaratan kesehatan masyarakat dan lingkungan. Hal tersebut adalah kesatuan ruang dengan semua benda, daya, keadaan dan makhluk hidup termasuk manusia dan perilakunya yang mempengaruhi kelangsungan perikehidupan dan kesejahteraan manusia serta makhluk hidup lainnya (UU Lingkungan Hidup No.23 tahun 1997). Lingkungan dalam penelitian ini adalah lingkungan fisik atau lingkungan sekitar permukiman ${ }^{7}$. 
Jurnal Kesehatan Terpadu (Integrated Health Journal)

Vol. 12 No. 2, November 2021 (55-61)

ISSN 1978-7766 (Print) and ISSN 2597-9566 (Online)

Journal homepage: https://www.jurnalpoltekkesmaluku.com/index.php/JKT

Penyebab stunting dapat dipengaruhi oleh beberapa faktor, seperti sanitasi lingkungan, pengolahan makanan, dan juga pengetahuan ibu terhadap stunting. Sanitasi lingkungan yang tidak sehat akan mempengaruhi kesehatan anak balita dan pada akhirnya berdampak pada status gizi balita tersebut ${ }^{5}$. Selain itu, stunting juga terjadi karena penyebab langsung maupun tidak langsung. Penyebab langsung stunting adalah gizi ibu saat hamil, penyakit infeksi, dan gizi balita. Penyebab tidak langsung stunting adalah water, sanitation, and hygiene (WASH). WASH terdiri dari sumber air minum, kualitas fisik air minum, kepemilikan jamban, dan kebiasaan cuci tangan ${ }^{8}$.

Penilaian status gizi balita dilakukan dengan membandingkan hasil pengukuran panjang/tinggi badan dengan standar antropometri anak. Klasifikasi penilaian status gizi berdasarkan indeks antropometri sesuai dengan kategori status gizi pada WHO Child Growth Standards untuk anak usia 0-5 tahun dan The WHO Reference 2007 untuk anak 5-18 tahun ${ }^{13}$.

Berdasarkan hasil penelitian yang dilakukan pada wilayah penelitian diketahui bahwa sanitasi lingkungan dengan status gizi berdasarkan indeks TB/U menunjukkan adanya hubungan yang bermakna ( $p$-value $<0.05)$. Sanitasi lingkungan yang buruk berdampak pada masalah gizi masa lampau dari seorang anak balita. Sanitasi lingkungan sangat penting diperhatikan karena berdampak pada masalah gizi dalam jangka panjang. Hasil ini didukung oleh hasil penitian yang dilakukan oleh Yuliani Soeracmad, 2020 diperoleh data faktor risiko pengamaan sampah rumah dan juga pembuangan air limbah memiliki $p$-value sebesar 0.000 $(p<0,05)$, maka secara statistik bermakna antara pengamanan sampah rumah tangga terhadap kejadian stunting/pendek ${ }^{14}$.

Masalah stunting/pendek mengindikasikan adanya masalah gizi kronis yang dipengaruhi dari kondisi ibu, masa ketika janin dalam masa kehamilan, dan masa bayi/balita, termasuk penyakit yang diderita selama masa balita. Balita yang mengalami gizi buruk tidak hanya berdampak dalam jangka pendek, apabila tidak diatasi dengan benar akan berdampak dalam jangka panjang dalam siklus kehidupannya. Bayi dengan BBLR akan sangat rentan terhadap kematian, masalah perkembangan mental, serta penyakit kronis ketika dewasa. Kondisi sanitasi lingkungan yang buruk, air minum yang tidak sehat, dan perilaku yang tidak higienis menjadi salah satu faktor penyebab terjadinya penyakit diare pada bayi atau balita. Penyakit diare yang terus menerus atau terjadi berulang-ulang pada bayi/balita akan menyebabkan kekurangan gizi. Hal tersebut dikarenakan oleh rusaknya mukosa usus oleh bakteri fecal yang mengakibatkan terjadinya gangguan absorbsi zat gizi ${ }^{3}$.

Hal ini berdasarkan hasil penelitian lain bahwa sumber air yang menggunakan air sumur meningkatkan risiko balita mengalami stunting 0,13 kali lebih tinggi dibandingkan dengan dengan sumber air yang sudah diolah (PAM). Dari analisis tersebut menunjukkan faktor risikonya kecil namun sudah mengindikasikan ada pengaruh sanitasi lingkungan dengan kejadian stunting. Selain itu didukung oleh penelitian yang lain menunjukkan bahwa anak yang berasal dari keluarga dengan sumber air yang tidak terlindung dan jenis jamban yang tidak layak mempunyai risiko mengalami stunting 1,3 kali lebih tinggi dibandingkan dengan anak yang berasal dari keluarga dengan sumber air terlindung dan jenis jamban yang layak ${ }^{(14,10)}$.

Upaya lain yang dapat dilakukan untuk mengurangi kejadian stunting pada balita di Indonesia, dibutuhkan intervensi gizi sensitif dengan perbaikan sanitasi lingkungan, pembangunan konstruksi jamban yang memenuhi syarat kesehatan, melakukan upaya promotif kesehatan dengan edukasi untuk meningkatkan kesadaran masyarakat agar tidak melakukan perilaku open defecation, dan pembuangan tinja termasuk tinja balita harus pada jamban. Tindakan tersebut bertujuan untuk mencegah fecal transmission sebagai vektor pembawa penyakit pada manusia dan lingkungan sekitarnya. Dengan demikian dapat memutuskan mata rantai penyebaran penyakit seperti diare, environmental enteric dysfunction (EED), cacingan, dan mengurangi kejadian stunting pada balita di Indonesia9 . 
Jurnal Kesehatan Terpadu (Integrated Health Journal)

Vol. 12 No. 2, November 2021 (55-61)

ISSN 1978-7766 (Print) and ISSN 2597-9566 (Online)

Journal homepage: https://www.jurnalpoltekkesmaluku.com/index.php/JKT

\section{SIMPULAN}

Berdasarkan penelitian ini dapat disimpulkan bahwa terdapat hubungan yang bermakna antara sanitasi lingkungan dengan indeks status gizi TB/U ( $p$-value $<0.05)$. Sanitasi lingkungan yang buruk berpengaruh pada masalah gizi balita, sehingga sanitasi lingkungan sangat penting diperhatikan karena berdampak pada masalah gizi dalam jangka panjang.

\section{SARAN}

Diharapkan masyarakat lebih meningkatkan pengetahuan tentang sarana sanitasi kawasan pesisir pantai dengan mengikuti sosalisasi petugas tenaga kesehatan yang menyangkut sarana sanitasi sehingga tercipta sarana sanitasi yang baik pada daerah kawasan pesisir pantai. Sosialisasi dan dukungan yang kuat dari keluarga atau orang terdekat dan tenaga kesehatan sangat diperlukan agar pemenuhan gizi balita lebih optimal. Diharapkan semua pihak dapat memberikan dukungan terhadap pemenuhan gizi guna mencegah terjadinya stunting pada balita.

\section{UCAPAN TERIMA KASIH}

Peneliti menyampaikan ucapan terima kasih kepada Direktur dan Ketua Jurusan Gizi Poltekkes Kemenkes Maluku serta kepada semua pihak yang memiliki kontribusi terhadap penelitian ini yaitu responden dan rekan satu tim penelitian.

\section{RUJUKAN}

1. Adriany, F., Hayana, H., Nurhapipa, N., Septiani, W., \& Sari, N. P. Hubungan Sanitasi Lingkungan dan Pengetahuan dengan Kejadian Stunting pada Balita di Wilayah Puskesmas Rambah. Jurnal Kesehatan Global, 4(1), 17-25. 2021. https://doi.org/10.33085/jkg.v4i1.4767

2. Anonim. Tinnginya Balita Penderita Stunting Di Maluku Dan Perjuangan Widya. 2019. Diakses 8 Desember 2019

3. Annita, Henny Suzana Mediani, W. R. Hubungan Faktor Air dan Sanitasi dengan Kejadian Stunting pada Balita di Indonesia. Jurnal Obsesi : Jurnal Pendidikan Anak Usia Dini, 5(2), 1035-1044. 2020. https://doi.org/10.31004/obsesi.v5i2.521

4. Dinas Kesehatan DIY. Sanitasi Dan Stunting. Dinkesjogja, 1995, 2-4. 2017. https://www.dinkes.jogjaprov.go.id/berita/detail/sanitasi-stunting-sanitasi--dan-stunting

5. Holil M. Par'i, D. Penilaian Status Gizi. In Bahan Ajar: Vol. Cetakkan P (2017th ed.). http://bppsdmk.kemkes.go.id/pusdiksdmk/wp-content/uploads/2017/11/Penilaian-Status-GiziFinal-sc.pdf

6. Kusumawati, E., Rahardjo, S., \& Sari, H. P. Model Pengendalian Faktor Risiko Stunting pada Anak Usia di Bawah Tiga Tahun. Jurnal Kesehatan Masyarakat, 9(3), 249-256. 2013

7. Muhammad Fadly, Anwar, M. F. N. Pantai Losari Kota Makassar Sanitation Quality of The Restaurant in The Tourism Destination Losari Beach Makassar Muhammad Fadly , Anwar , Muhammad Fajaruddin Natsir Bagian Kesehatan Lingkungan Fakultas Kesehatan Masyarakat Universitas Hasanuddin Pendahuluan. 5. 2017. file:///C:/Users/Acer Aspire ES11/Downloads/89562365.pdf

8. Niken Luluk Cahyani. Partisipasi Kepala Keluarga Dalam Perbaikan Sanitasi Lingkungan Permukiman Di Kelurahan Rowosari Kecamatan Tembalang Kota Semarang. 2013. Diakses 9 Desember 2019

9. Olo, Annita, Henny Suzana Mediana, Windy Rakhmawati. Hubungan Faktor Air dan Sanitasi Dengan Kejadian Stunting Pada Balita Di Indonesia. Jurnal Obsesi:Jurnal Pendidikan Anak Usia Dini. Volume 5 Issue 2 (2021) Pages 1113-1126. DOI: 10.31004/obsesi.v5i2.521

10. Prasetyo, Anggi, Robitah Asfur. GAmbaran Sanitasi Lingkungan Pada Stunting Di Desa Secanggang Kabupaten Langkat. Jurnal Ilmiah Kohesi Vol 5 Nomor 2 April 2021 hal 14-23. 
Jurnal Kesehatan Terpadu (Integrated Health Journal)

Vol. 12 No. 2, November 2021 (55-61)

ISSN 1978-7766 (Print) and ISSN 2597-9566 (Online)

Journal homepage: https://www.jurnalpoltekkesmaluku.com/index.php/JKT

11. Priestnall, S. L., Okumbe, N., Orengo, L., Okoth, R., Gupta, S., Gupta, N. N., Gupta, N. N., Hidrobo, M., Kumar, N., Palermo, T., Peterman, A., Roy, S., Konig, M. F., Powell, M., Staedtke, V., Bai, R. Y., Thomas, D. L., Fischer, N., Huq, S., ... Chatterjee, R. Peraturan Menteri Kesehatan Republik Indonesia Nomor 2 Tahun 2020 Tentang Standar Antropometri Anak. 2020. Endocrine, 9(May), 6.6 https://www.slideshare.net/maryamkazemi3/stability-ofcolloids\%0Ahttps://barnard.edu/sites/default/files/inline/student_user_guide for_spss.pdf\%0Ahtt p://www.ibm.com/support\%0Ahttp://www.spss.com/sites/dmbook/legacy/ProgDataMgmt_SPSS17.pdf\%0Ahttps://www.n

12. Soeranto, D. A., Suprijanto, I., Farida, R., Krispratmadi, D., \& Sundoro, M. Atasi stunting dengan penyediaan infrastruktur dasar. 2018. Dinas PUPR

13. Soerachmad, Y., Ikhtiar, M., \& S, A. B. Hubungan Sanitasi Lingkungan Rumah Tangga Dengan Kejadian Stunting Pada Anak Balita Di Puskesmas Wonomulyo Kabupaten polewali Mandar Tahun 2019 Relationship of Household Environmental Sanitation with Stunting Occurrence in Toddler Children in Wonomulyo He. Jurnal Kesehatan Masyarakat, 5(2), 138-150. 2019

14. Tenggara, M. Widya MI Tak Ingin Stunting Rampas Masa Depan Generasi Maluku. 2020. Diakses April 2020 